\title{
ANÁLISE DA ESTABILIDADE GLOBAL DE UM MURO LONGITUDINAL EM GABIÃO PARA PROTEÇÃO DE MARGEM EM CURSO D’ÁGUA
}

\section{Marina Cardoso da Silva}

Graduanda em Engenharia Civil pela Universidade Augusto Motta (UNISUAM),

Rio de Janeiro, RJ, Brasil

marinacsl@yahoo.com

\section{Celso Richard da Costa Leal}

Graduando em Engenharia Civil pela Universidade Augusto Motta (UNISUAM),

Rio de Janeiro, RJ, Brasil

celsorcleal@gmail.com

\section{Luiz Eduardo Amancio Aguiar}

Mestre em Engenharia Civil pela Universidade Federal Fluminense (UFF),

Niterói, RJ, Brasil

leduaguiar@yahoo.com.br

\section{RESUMO}

O presente artigo aborda um dos propósitos para a garantia de ambientes seguros, em foco, aqueles que circundam cursos d'água, ameaçados por desequilíbrios em terrenos que os margeiam, através do combate às forças externas, provocadas, por exemplo, pela ação humana, ou forças internas, pela alteração da resistência do solo por processos naturais. Estes desequilíbrios podem ser evitados e/ou tratados a partir de intervenções adequadas. Através de perspectiva analítica, o objetivo deste estudo visa a compreensão e a avaliação da estabilidade contra a ruptura global de uma estrutura de Muro Longitudinal em Gabião investigando e explicando o emprego desta técnica de controle para estabilização e proteção de margens instáveis para um trecho do Rio Pardo, localizado 
no município de Ibatiba, no Estado do Espírito Santo. Utiliza-se da observação in situ para reconhecimento do estado da margem local e descreve-se o dimensionamento da estrutura, bem como o sistema da estabilidade global através de software GawacWin ${ }^{\circledR}$ proposto para verificação, em parte, da eficiência técnica e do cumprimento da segurança da obra.

Palavras-chave: Estabilidade. Proteção de margens. Cursos d'água. Muro longitudinal. Gabião.

\title{
ANALYSIS OF THE GLOBAL STABILITY OF A LONGITUDINAL WALL IN GABION FOR PRO- TECTION OF MARGIN IN COURSE OF WATER
}

\begin{abstract}
The present article addresses one of the purposes for the assurance of safe environments, in focus, those that surround watercourses, threatened by imbalances in lands that border them, by combating external forces caused, for example, by human action, or internal forces, by altering soil resistance by natural processes. These imbalances can be avoided and/or dealt with through appropriate interventions. Through an analytical perspective, the objective of this study is to understand and evaluate the stability against the global rupture of a Longitudinal Wall structure in Gabion by investigating and explaining the use of this control technique to stabilize and protect unstable margins an excerpt from Rio Pardo, located in the municipality of Ibatiba, in the State of Espírito Santo. In situ observation is used to recognize the state of the local margin and the design of the structure is described, as well as the system of global stability through GawacWin ${ }^{\circledR}$ software proposed for verification, in part, of the technical efficiency and the safety performance of the work.
\end{abstract}

Keywords: Stability. Margin protection. Water course. Longitudinal Wall. Gabion. 


\section{INTRODUÇÃO}

Sobre a instabilidade das margens de cursos d'água, estas são provocadas pela ação humana, decorrente do crescimento populacional exacerbado, e consequente ocupação inadequada em áreas margeadas por rios, canais ou córregos, com a ação da retirada da vegetação ali existente, antes exercendo função de proteção natural, por exemplo, ou por processos erosivos naturais condicionados pelas correntes, devido ao aumento do fluxo, apresentando-se superiores ao escoamento dominante, gerando mudança no comportamento deste e manifestando alterações na forma matriz das superfícies limítrofes e sólidas do canal que possuem maior exposição ao desgaste (Antão, 2012).

Para que se mantenha o curso d'água natural e haja o controle de erosão de solos das margens, a proteção dos terrenos se dá, então, a partir da aplicação de estruturas a fim de travar as forças que permitam o avanço das águas ao sentido dos terrenos e bens circundantes existentes nas zonas as quais seja necessário proteger.

Deve-se levar em conta fatores preponderantes e aplicar como princípios fundamentais a avaliação do estado das margens, conhecendo-se as características geotécnicas destas, as influências e as cargas atuantes existentes, segundo Fracassi (2017), para referenciá-los ao dimensionamento, e então, reuni-las para um estudo de forma a tornar a escolha da técnica de reabilitação, o mais eficaz e adequada.

Neste estudo, a ênfase relaciona-se ao estudo da estrutura de um muro longitudinal em gabião, incitando a verificação da estabilidade e resistência contra a ruptura global da mesma a fim de que não haja o escorregamento ao longo da superfície que a contorna, conforme Gerscovich, Danziger e Saramago (2016) expressam, e perante a investigação da eficiência da intervenção para algumas condições de segurança fundamentais relacionadas ao caso.

A análise apresenta-se pelo estudo de caso através dos resultados do projeto da estrutura em gabião sugerido para recuperação e recomposição das margens de um trecho do Rio Pardo, localizado no município de Ibatiba, no Estado do Espírito Santo, referenciando-os à norma NBR 11682 (ABNT, 2009). 


\section{ESTRUTURAS LONGITUDINAIS}

\subsection{Aspectos dos Muros Longitudinais}

Entre as variadas alternativas para intervenções em cursos d'água, os muros longitudinais podem ser inseridos ao mesmo conceito de muros de contenção por gravidade ou muros de arrimo, sendo sua estabilidade garantida substancialmente, conforme evidencia Barros (2015), através do seu peso próprio e, em alguns casos, do peso incorporado por meio de parte de solo, que combatem os empuxos horizontais existentes.

Para estruturas hidráulicas, os muros longitudinais em gabião apresentam-se como uma das soluções mais usualmente utilizadas, por possuírem uma gama de atributos e características funcionais singulares, desempenhando importante função para proteção dos efeitos erosivos do fluxo e contenção do empuxo do solo das margens. Estas estruturas devem, portanto, ser projetadas para contrapor-se e suportar as forças provenientes, oferecer equilíbrio e atenuação de perda do terreno e podem destinar-se ao controle de erosão e sinuosidade, à contenção de margem de canal de vazão normal e à proteção contra inundações (Fracassi, 2017).

Devem-se analisar os aspectos hidráulicos, em teor de resistência e geotécnicos, em teor de estabilidade, que envolvam essas obras longitudinais. Usualmente, a verificação do muro em gabião para obras hidráulicas é feita incluindo cálculos, como: tensão de arraste, velocidade admissível, crítica e de contato com o solo, ação de ondas (no caso de cursos d' água navegáveis) e deformações. Contudo, não serão descritas estas verificações, devido apenas à análise de estabilidade global ser foco principal deste artigo.

Fracassi (2017) exalta, ainda, que o bom comportamento das estruturas de muros longitudinais dependerá de forma elementar da definição correta da cota de fundação, que exercerá a função de suportar, em parte, os processos de erosão ou sedimentação generalizada. 


\subsection{Muros em Gabião}

Conceituado, no âmbito de obras hidráulicas, pelo elevado suporte ao peso da água e definidos como estruturas tradicionais de contenção, os muros em gabião apresentam-se em alguns tipos, tendo em comum entre estes os aspectos que oferecem estabilidade contra a ruptura dos maciços de terra, sendo passíveis suas aplicações em variadas intervenções eficazes da engenharia por constituírem-se: flexíveis, acomodando-se a recalques diferenciais, não sendo necessária a realização de fundação profunda; permeáveis, e, portanto, autodrenantes, ao aliviar completamente o empuxo hidrostático sobre a estrutura; monolíticas, onde todos os elementos que a compõe unem-se oferecendo homogeneidade a todos os pontos da estrutura; resistentes, apresentando vantagens na sua concepção de telas metálicas, através dos elementos de malha hexagonal de dupla torção, revestidas com fios de liga de zinco-alumínio, que preservam a forma e a flexibilidade através da distribuição das tensões no caso de ruptura de um dos arames, absorvendo as deformações excessivas; duráveis, por serem revestidos com uma camada de proteção de material plástico extrudido contra ação da corrosão, contribuindo para aumento da vida útil da estrutura e para aplicação em ambientes agressivos e com presença de água; e armadas, onde as malhas possuem elevada rigidez e resistência mecânica com função de conter as pedras em seu interior.

Além disso, há fácil integração das estruturas ao meio circundante, não oferecendo obstáculo ao fluxo de água e permitindo um bom aspecto visual. Constituem um conjunto de versatilidade, praticidade, facilidade de execução e manutenção.

Importante salientar, como aborda Fracassi (2017), que a composição granulométrica do terreno é menor que a do material de preenchimento que compõe o gabião, este material constituindo vazios, os quais permitirão o atravessamento de partículas finas causado pelo fluxo das águas subterrâneas ou subsuperficiais. É necessária, então, a colocação de um tipo de filtro, atrás do muro, para impedir que estas partículas não vazem ao sentido do leito, utilizando geralmente uma manta geotêxtil que permita a permeabilidade da estrutura. Esta ação oportuniza, ainda, que os efeitos de pressões da água na estrutura sejam atenuados.

A escolha do tipo de gabião para o projeto deste estudo refere-se ao tipo caixa. 
Para este, pode ser feita a disposição de caixas retangulares, de forma a apresentar paramento escalonado no sentido externo ou interno ao terreno (Figura 1).

Figura 1 - Muro de gabiões com paramento escalonado externo e interno.
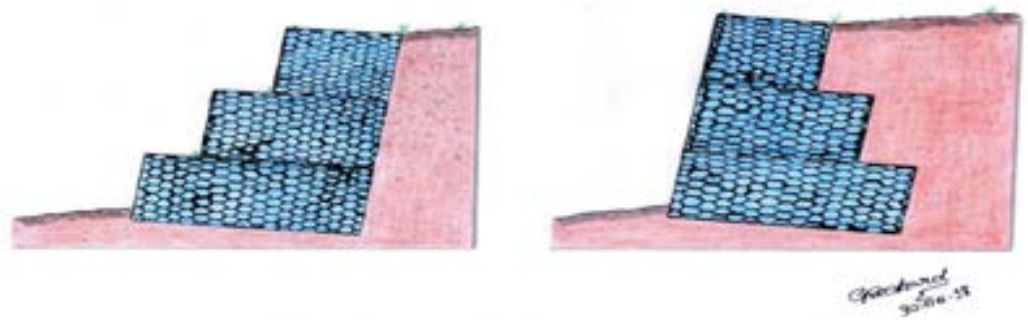

Fonte: (Autores, 2018).

\subsection{Métodos de Cálculo}

O equilíbrio entre a interação do maciço de terra e uma estrutura de contenção se torna complexo devido às condicionantes deste conjunto. Este equilíbrio deve atender condições de estabilidade específicas.

Para análise de estabilidade global, foco deste estudo, verifica-se a ruptura ao longo de uma superfície circular no interior do maciço que contorna o muro de gabiões. Esta superfície de ruptura atravessa, dessa forma, tanto o solo arrimado à direita da estrutura quanto o solo de fundação e o maciço à esquerda do muro.

Alguns modelos teóricos auxiliam na simplificação do estudo, os quais consideram as características dos materiais como o peso específico e de resistência, para solo e estrutura e ainda, a coesão e o ângulo de atrito para o solo, além da geometria e das condições locais.

O princípio de cálculo utilizado referencia-se ao Equilíbrio Limite, o qual o software GawacWin ${ }^{\circledR}$ faz uso, bem como o método Bishop, que conceitua-se pelo balancea- 
mento entre as forças de ruptura e esforços resistentes, determinando a superfície de ruptura mais crítica.

\subsubsection{Método de Bishop}

Método que emprega superfícies cilíndricas, dividindo-se em lamelas, como forma de determinação do coeficiente de segurança associado à mobilização parcial da resistência por toda a extensão da superfície de ruptura.

É considerada uma superfície de ruptura cilíndrica (Figura 2), já que esta se aproxima de forma mais realista das rupturas observadas.

Figura 2 - Seção de ruptura global.

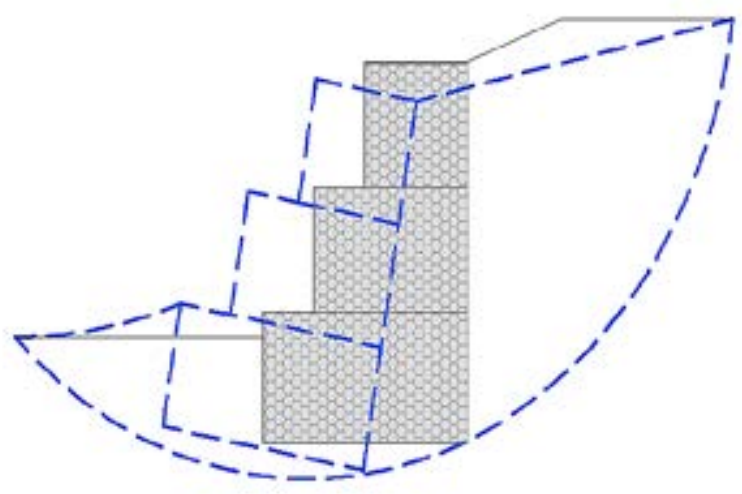

Fonte: (Adaptado do Manual da Maccaferri ${ }^{\circledR}$ - Obras de contenção, 2015).

A procura do arco mais crítico de forma automática, pelo software GawacWin ${ }^{\circledR}$ é selecionada e otimizada através do algoritmo minimizador Simplex, o qual permite que se encontrem valores ideais em situações em que diversos aspectos precisam ser respeitados, para a verificação da estabilidade global do conjunto solo/estrutura, como camadas de solos diferentes, pressões neutras, lençol freático, sobrecargas, etc. 
As forças que agem sobre cada uma das lamelas analisadas pelo método são mostradas na Figura 3. São estas: o peso próprio da lamela "P", as forças normal "N" e tangencial " $\mathrm{T}$ " que agem na superfície de ruptura, as forças horizontais " $\mathrm{H} 1$ " e " $\mathrm{H2}$ " e as verticais "V1" e "V2" que agem nas faces laterais.

Figura 3 - Forças atuantes em cada lamela.

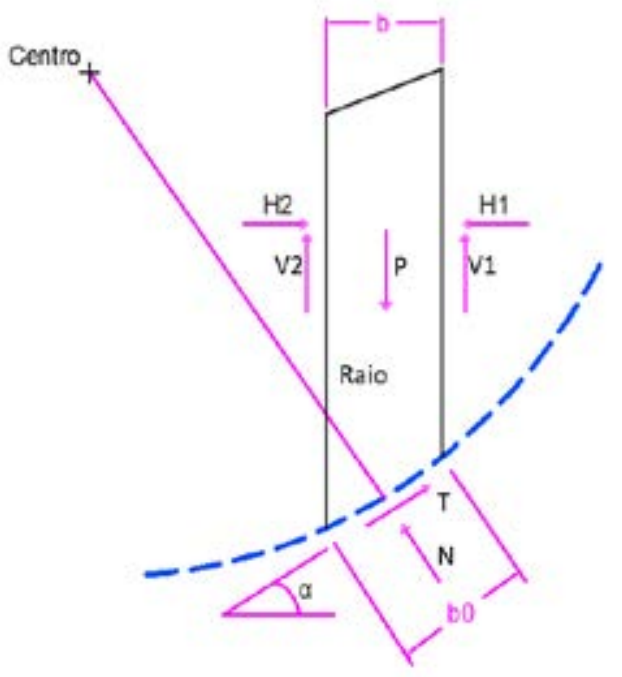

Fonte: (Adaptado do Manual da Maccaferri ${ }^{\circledR}$ - Obras de contenção, 2015).

Fazendo-se o equilíbrio de forças na direção vertical, obtém-se:

A força tangencial " $\mathrm{T}$ " é dada por:

Onde " $\mathrm{F}$ " é o coeficiente de segurança, admitido para todas as lamelas, contra a ruptura, e "s" é a resistência ao cisalhamento na lamela, dada por:

Admitindo-se que $=0$ ", tem-se:

A resistência "s" fica então: 
Fazendo-se o equilíbrio global de momentos em relação ao centro do arco de ruptura e admitindo que a somatória dos momentos das forças laterais entre as lamelas é nula, tem-se:

Então:

Obtém-se, finalmente, o valor do Fator de Segurança $(F)$, por:

Devem-se pesquisar várias superfícies de ruptura até se encontrar a mais crítica (menor valor de "F"). Para isso, analisa-se separadamente cada lamela considerada, necessitando utilizar-se de três parâmetros: posição horizontal e posição vertical do centro " $O$ ", além do valor do raio " $\mathrm{R}$ " a que o coeficiente de segurança se refere e o número de arcos analisados.

A análise da superfície dos vários arcos de cada lamela ocorre à direita da estrutura, ao solo de fundação e o maciço ao longo do muro. Estes elementos compõem: a distância horizontal entre o muro e o ponto de cruzamento do arco de ruptura com a superfície superior do solo à esquerda do muro (L1); a distância vertical entre o extremo interior direito da base e o arco de ruptura (L2); a distância horizontal entre o topo do muro e o ponto de cruzamento do arco de ruptura com a superfície superior do terrapleno à direita da estrutura (L3), além da máxima profundidade que os arcos pesquisados podem alcançar.

Estas variadas análises tornam a pesquisa complexa. Portanto, utiliza-se o software GawacWin ${ }^{\circledR}$ desenvolvido e disponibilizado pelo grupo Maccaferri ${ }^{\circledR}$, sendo este fundamental para análise de estabilidade do muro em gabião. $O$ sistema faz todo o cálculo utilizando a metodologia do Equilíbrio Limite e Bishop, com a ferramenta Simplex. 


\subsection{Metodologia do estudo de caso}

Iniciou-se o estudo de caso com a avaliação da área através dos projetos de caráter emergencial do Instituto de Obras Públicas do Espírito Santo - IOPES, que comprovaram a existência de um processo de escorregamento e erosão em trechos de área sinuosa, às margens do Rio Pardo, no município de Ibatiba (Figura 4), em decorrência da elevada precipitação pluviométrica ocorrida em dezembro de 2013.

Figura 4: Local referente à intervenção do muro em gabião, Ibatiba, Espírito Santo.

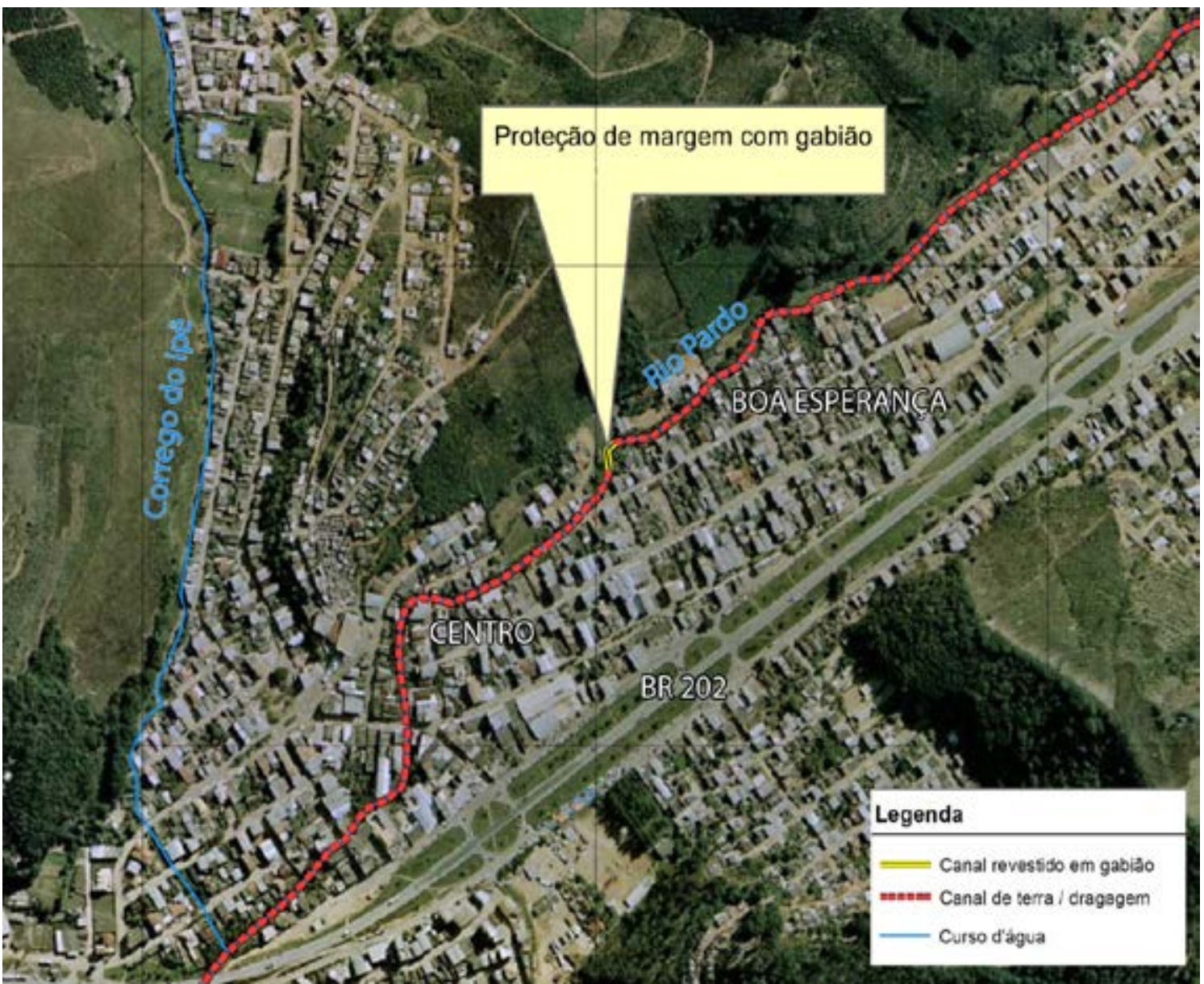

Fonte: (Mapa cartográfico - Adaptado de Planos Municipais de Redução de Risco Geológico - PMRR, 2014.) 
É fundamental o conhecimento das propriedades do solo, sem elas a utilização e o desempenho da estrutura ficam comprometidos.

Diante disso, como não há informações sobre a realização de ensaios laboratoriais para as características do solo, estas podem ser estimadas utilizando como referência a Tabela 1, que expressa valores típicos dos parâmetros geotécnicos de peso específico e ângulo de atrito.

Tabela 1 - Valores típicos do peso específico e ângulo de atrito de solos.

\begin{tabular}{|c|c|c|c|}
\hline Tipo de solo & $\gamma\left(\mathbf{k N} / \mathbf{m}^{\mathbf{3}}\right)$ & Tipo de solo & $\Phi^{\prime}$ (graus) \\
\hline Areia uniforme, fofa & 17 & Areia angular, fofa & $32-36$ \\
\hline Areia uniforme, compacta & 20 & Areia angular, compacta & $35-45$ \\
\hline Areia siltosa, fofa & 18 & Areia sub-angular, fofa & $30-34$ \\
\hline Areia siltosa, compacta & 19 & Areia sub-angular, compacta & $34-40$ \\
\hline Silte & $17-19$ & Areia arredondada, fofa & $28-32$ \\
\hline Silte argiloso & $16-18$ & Areia arredondada, compacta & $32-38$ \\
\hline Argila inorgância & $15-17$ & Areia siltosa, fofa & $25-35$ \\
\hline Argila orgânica & $13-16$ & Argila siltosa, compacta & $30-36$ \\
\hline
\end{tabular}

Fonte: (Adaptado do Manual da Maccaferri ${ }^{\circledR}$ - Obras de contenção, 2015).

De acordo com as caraterísticas reunidas em projeto, os valores considerados para o solo local de fundação, e para camada de terrapleno, foram respectivamente:

- $\quad \gamma($ Peso específico $)=18 \mathrm{kN} / \mathrm{m}^{3}$ e $19 \mathrm{kN} / \mathrm{m}^{3}$

- $\Phi$ (ângulo de atrito) = 30 graus e 30 graus

- $c($ coesão $)=10 \mathrm{kN} / \mathrm{m}^{2}$ e $20 \mathrm{kN} / \mathrm{m}^{2}$

Observa-se que para os dados referenciados ao projeto, o solo de fundação compõe-se por areia siltosa fofa, com alguma coesão estimada e o solo de terrapleno compõe-se por areia siltosa compacta, com valor de coesão estimada em dobro, o que se justifica pela melhor resistência imposta a este por processos de compactação. Ambos possuem coesão devido ao material silte. Para considerações de empuxo, os solos coesivos, provocam a ocorrência de uma força adicional sobre a superfície de ruptura.

Gerscovich (2016) exprime, em tese, que os estados limites, aqueles que designam os requisitos para funcionamento adequado da estrutura, são determinados com 
base nos parâmetros reais de resistência e de solicitação do conjunto e que a avaliação da segurança de um maciço de terra, é um fator controlador de projetos neste tipo de intervenção, normalmente definido por valores mínimos sob a forma de um coeficiente de segurança a ser estabelecido como critério, por exemplo, para a probabilidade de ruptura, condicionados pela NBR 11682 (ABNT, 2009).

De acordo com a NBR 11685 - Estabilidade de Taludes, em relação ao nível de segurança, este depende inicialmente da avaliação dos riscos que envolvem um projeto, definindo-se um que atenda às especificações contra danos materiais e ambientais (Tabela 2) e danos contra perdas humanas (Tabela 3). O valor definido considera as condições atuais, bem como, o uso futuro da obra (Gerscovich, 2016).

Tabela 2 - Nível de segurança desejado contra danos materiais e ambientais.

\begin{tabular}{|l|l|}
\hline $\begin{array}{l}\text { Nível de segu- } \\
\text { rança }\end{array}$ & Critérios \\
\hline Alto & $\begin{array}{l}\text { Danos materiais: locais próximos a propriedades de alto valor histórico, social ou pa- } \\
\text { trimonial, obras de grande porte e áreas que afetam serviços essenciais. Danos am- } \\
\text { bientais: locais sujeitos a acidentes ambientais graves, tais como nas proximidades de } \\
\text { oleodutos, barragens de rejeito e fábricas de produtos tóxicos }\end{array}$ \\
\hline Médio & $\begin{array}{l}\text { Danos materiais: locais próximos a propriedades de valor moderado. Danos ambien- } \\
\text { tais: locais sujeitos a acidentes ambientais moderados }\end{array}$ \\
\hline Baixo & $\begin{array}{l}\text { Danos materiais: locais próximos a propriedades de valor reduzido. Danos ambien- } \\
\text { tais: locais sujeitos a acidentes ambientais reduzidos }\end{array}$ \\
\hline
\end{tabular}

Fonte: (Estabilidade de Taludes, 2016).

Tabela 3 - Nível de segurança desejado contra perdas humanas.

\begin{tabular}{|l|l|}
\hline $\begin{array}{l}\text { Nível de segu- } \\
\text { rança }\end{array}$ & Critérios \\
\hline Alto & $\begin{array}{l}\text { Áreas com intensa movimentação e permanência de pessoas, como edificações } \\
\text { públicas, residenciais ou industriais, estádios, praças e demais locais urbanos, ou } \\
\text { não, com possiblidade de elevada concentração de pessoas } \\
\text { Ferrovias e rodovias de tráfego intenso }\end{array}$ \\
\hline Médio & $\begin{array}{l}\text { Áreas e edificações com movimentação e permanência restrita de pessoas } \\
\text { Ferrovias e rodovias de tráfego moderado }\end{array}$ \\
\hline Baixo & Áreas e edificações com movimento e permanência eventual de pessoas \\
& Ferrovias e rodovias de tráfego reduzido \\
\hline
\end{tabular}

Fonte: (Estabilidade de Taludes, 2016). 
Os valores de são recomendados, considerando-se, as solicitações previstas para o período de construção e vida útil da obra (Tabela 4).

Tabela 4 - Fatores de segurança mínimos para escorregamentos.

\begin{tabular}{|c|c|c|c|}
\hline \multirow{2}{*}{$\begin{array}{l}\text { Nível de segurança contra da- } \\
\text { nos materiais e ambientais }\end{array}$} & \multicolumn{3}{|l|}{$\begin{array}{l}\text { Nível de segurança contra danos a vidas huma- } \\
\text { nas }\end{array}$} \\
\cline { 2 - 4 } & Alto & Médio & Baixo \\
\hline Alto & 1,5 & 1,5 & 1,4 \\
\hline Médio & 1,5 & 1,4 & 1,3 \\
\hline Baixo & 1,4 & 1,3 & 1,2 \\
\hline
\end{tabular}

Fonte: (Estabilidade de Taludes, 2016).

A partir das características locais em estudo, o nível de segurança estabelecido contra danos materiais e ambientais, pode ser definido como médio, e o nível de segurança estabelecido contra perda de vidas humanas, pode ser definido como alto. Admite-se, então, um fator de segurança mínimo em 1,5.

Os dados geotécnicos do local, as especificações técnicas da estrutura além da influência externa considerados no projeto da obra referem-se:

- À geometria da camada de solo de fundação, sendo esta com altura inicial de 0,10m, comprimento de 20,00m e inclinação de 0 graus, contendo as propriedades do solo, este com peso específico de $18,00 \mathrm{kN} / \mathrm{m}^{3}$, ângulo de atrito de 30,00 graus e coesão de $10,00 \mathrm{kN} / \mathrm{m}^{2}$.

- Aos materiais a serem utilizados na confecção do muro, sendo a inclinação em que este será construído igual a 0 graus, com seu material de enchimento em pedra de mão, de peso específico igual a 25,00 kN/ $\mathrm{m}^{3}$ e porosidade igual a $30,00 \%$. Considera-se somente a utilização de geotêxtil no terrapleno, e não sob a base do muro. A malha é do tipo $8 \mathrm{x}$ 10, com diâmetro do arame $\varnothing=2,7 \mathrm{~mm}$.

- Às camadas do muro, com geometria considerada pelo arranjo em três camadas, sendo a primeira, de largura 2,00m, altura de $1,00 \mathrm{~m}$, 
sem deslocamento; a segunda, de largura 1,50m, altura de 1,00, sem deslocamento; a terceira, de largura 1,00m, altura de 1,00, sem deslocamento.

- Aos dados da geometria da camada de terrapleno, que permite descrever a situação em campo quando estruturas em gabiões são construídas como contenções de corte, necessitando realizá-lo no maciço e reconstituí-lo de forma a possibilitar a construção do muro, posteriormente efetuando o reaterro dessa área. Esta camada constitui-se de altura inicial de 1,00m, inclinação de 45 graus, peso específico de $19 \mathrm{kN} / \mathrm{m}^{3}$, coesão de $20 \mathrm{kN} / \mathrm{m}^{2}$ e ângulo de atrito de 30,00 graus.

- Às cargas à que a intervenção pode estar submetida, estas sendo distribuídas ou pontuais, aplicadas sobre o terrapleno ou sobre a própria estrutura em gabiões. Considera-se um carregamento uniforme sobre o terrapleno de $50 \mathrm{kN} / \mathrm{m}^{2}$.

O dimensionamento dos muros em gabião usados no projeto e na execução da obra pode ser observado na Figura 5.

Figura 5 - Dimensionamento dos muros em gabião para intervenção no Rio Pardo.
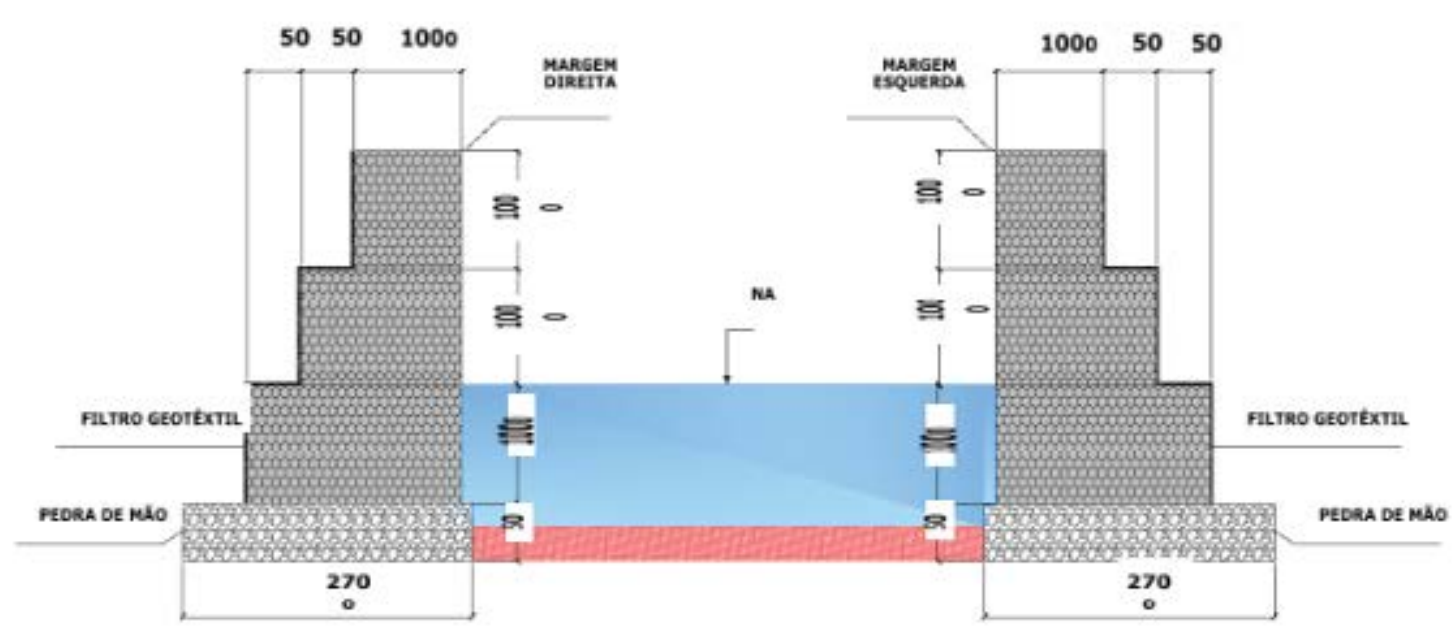

Fonte: (Adaptado do Projeto de Intervenção do Instituto de Obras Públicas do Espírito Santo - IOPES, 2004). 


\subsection{Análise da Estabilidade Global}

Os dados definidos para o projeto, apresentados anteriormente são lançados no software supracitado, acionando-se os comandos para a análise de estabilidade global do muro longitudinal em gabião.

Todos os dados de entrada do programa podem ser imputados de forma automática. Os dados de distância inicial à esquerda (L1), distância inicial à direita (L2) e distância inicial abaixo da base (L3), referem-se à superfície de ruptura no limite do arco. Consideram-se: $\mathrm{L} 1=1,10 \mathrm{~m} ; \mathrm{L} 2=4,50 \mathrm{~m}$ e $\mathrm{L} 3=0,00$.

Para análise da estabilidade global do problema, emite-se um relatório contendo os dados do problema com a modelagem da estrutura e os resultados alcançados.

Observam-se as características das análises (Figura 6) e os resultados obtidos pelo relatório (Tabela 5), referentes às coordenadas $X$ e $Y$, as quais se atribuem ao centro do círculo de falha para o qual o programa calcula o coeficiente de segurança, o raio da superfície de falha, a quantidade de lamelas analisadas e ao fator de segurança contra a ruptura global.

Tabela 5 - Resultado das análises da Estabilidade global.

\begin{tabular}{|c|c|}
\hline Dados da análise de Estabilidade Global & Resultados \\
\hline Centro do arco referente ao eixo X & $-0,14 \mathrm{~m}$ \\
\hline Centro do arco referente ao eixo Y & $4,62 \mathrm{~m}$ \\
\hline Raio do arco & $5,13 \mathrm{~m}$ \\
\hline Número de superfícies pesquisadas & 52 \\
\hline Coeficiente de Segurança contra Ruptura Global & 1,90 \\
\hline \multicolumn{2}{|c|}{ Fonte: (Relatório de análise do software GawacWin ${ }^{\circledR}$ ). }
\end{tabular}

Fonte: (Relatório de análise do software GawacWin ${ }^{\circledR}$ ). 
Figura 6 - Características das análises da Estabilidade global.

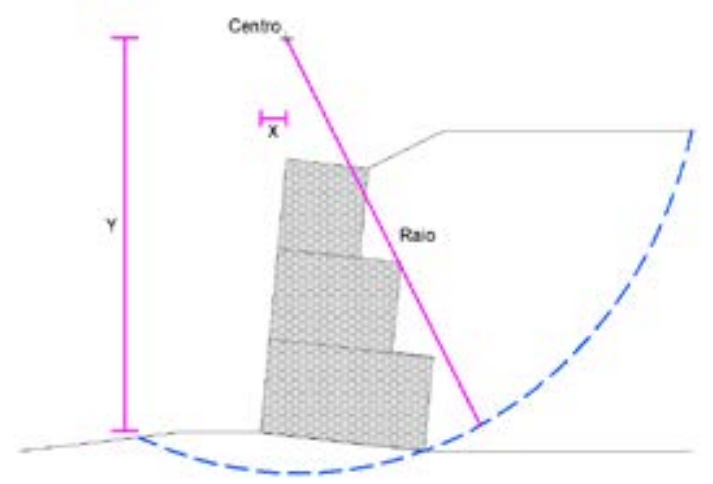

Fonte: (Autores, 2018).

Observa-se, assim, que os critérios de segurança foram atendidos de maneira satisfatória já que o fator de segurança contra ruptura global mais crítico, após a pesquisa das variadas seções através do software, foi de 1,9, acima do estabelecido para o projeto.

\section{CONSIDERAÇÕES FINAIS}

As análises de estabilidade global utilizando-se dos dados obtidos através de documentos referentes à obra se mostram eficientes, contudo o presente trabalho não se dispôs a realizar a descrição dos métodos empíricos e seus cálculos em sua totalidade para todas as formas de estabilidade que devem ser consideradas para este tipo de intervenção, apenas a estabilidade global.

A proposta inicial do projeto de dimensionamento e intervenção de estabilização e contenção das margens com gabiões cumpre a necessidade da garantia de segurança da estrutura, atendendo a área em risco, protegendo as margens erodidas, e oferecendo, ainda, conforto visual e arquitetônico.

O estudo demostra que a análise do sistema flexível foi realizada de forma sa- 
tisfatória. Todavia, a estrutura pode ser considerada mais estável, com a prevenção da erosão no pé do maciço, utilizando um conceito de experiência, o qual estabelece a inclinação de $6^{\circ}$ no sentido da margem para melhorar a estabilidade requerida.

Salienta-se a importância do princípio fundamental da não generalização da escolha de uma estrutura, em termos técnicos, ambientais e econômicos, já que cada caso apresenta caraterísticas, limitações e exigências particulares.

Incita-se o desenvolvimento futuro de trabalhos com a continuidade da análise funcional dos projetos estruturais de gabião existentes em maiores extensões do Rio Pardo, no município de Ibatiba, no Estado do Espírito Santo.

\section{REFERÊNCIAS}

ANTÃO, C. F. N. Seleção e Dimensionamento de Estruturas de Proteção de Margens de Rios. Aplicações Práticas. Dissertação de mestrado, Especialização em Hidráulica. Universidade do Porto, Portugal, 2012.

ASSOCIAÇÃO BRASILEIRA DE NORMAS TÉCNICAS. NBR 11682: Estabilidade de Taludes. Rio de Janeiro, 2009.

BARROS, P. L. A. Obras de Contenção. Manual Técnico da Macaferri ${ }^{\circledR}$. Macaferri ${ }^{\circledR}$ do Brasil, 2015. Disponível em: <https://www.maccaferri.com/br/documentos/manual-tecnico/> Acesso em: 25 de abril de 2018.

CONTRATO DE EMPREITADA EMERGENCIAL 006/2014 IBATIBA - META 02. Projeto de Estruturas de Contenção - Memorial Descritivo e de Cálculo - Estabilidade de Taludes. Prefeitura de Ibatiba, Espírito Santo, 2004. Disponível em: <https://ibatiba.es.gov.br/ 
Media/Prefeituralbatiba/Licitações/IOPES-006-IB2-MD-2.pdf> Acesso em: 30 de março de 2018.

FRACASSI, G. Proteção de rios com soluções Maccaferri. São Paulo: Oficina de textos, 2017.

GERSCOVICH, D. M. S. Estabilidade de taludes. São Paulo: Oficina de textos, 2016.

GERSCOVICH, D. M. S, DANZIGER, B. R., SARAMAGO, R. Contenções: teoria e aplicações em obras. São Paulo: Oficina de textos, 2016.

PLANO MUNICIPAL DE REDUÇÃO DE RISCO GEOLÓGICO E PLANO DIRETOR DE ÁGUAS PLUVIAIS/FLUVIAIS DE IBATIBA. Programa Municipal de Redução de Risco (PMRR). Secretaria de Saneamento, habitação e Desenvolvimento Urbano (SEDURB), Espírito Santo, 2014. Disponível em: <https://sedurb.es.gov.br/plano-de-reducao-de-risco-2> Acesso em: 26 de maio de 2018. 